Preprint

UCRL-JC-139666

\title{
Chemical Etch Effects on Laser-Induced Surface Damage Growth in Fused Silica
}

L.W. Hrubesh, M.A. Norton, W.A. Molander, P.J. Wegner, M. Staggs, S.G. Demos, J.A. Britten, L.J. Summers, E.F. Lindsey, and M.R. Kozlowski

This article was submitted to Annual Symposium on Optical Materials for High Power Lasers, Boulder, CO, October 16-18, 2000

U.S. Department of Energy

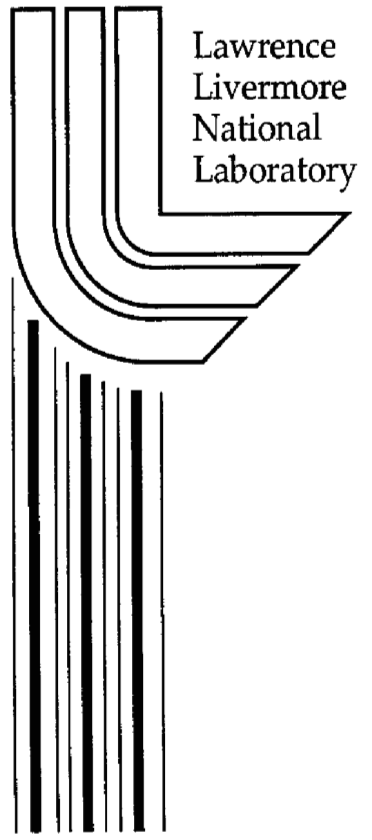

December 22, 2000 


\section{DISCLAIMER}

This document was prepared as an account of work sponsored by an agency of the United States Government. Neither the United States Government nor the University of California nor any of their employees, makes any warranty, express or implied, or assumes any legal liability or responsibility for the accuracy, completeness, or usefulness of any information, apparatus, product, or process disclosed, or represents that its use would not infringe privately owned rights. Reference herein to any specific commercial product, process, or service by trade name, trademark, manufacturer, or otherwise, does not necessarily constitute or imply its endorsement, recommendation, or favoring by the United States Government or the University of California. The views and opinions of authors expressed herein do not necessarily state or reflect those of the United States Government or the University of California, and shall not be used for advertising or product endorsement purposes.

This is a preprint of a paper intended for publication in a journal or proceedings. Since changes may be made before publication, this preprint is made available with the understanding that it will not be cited or reproduced without the permission of the author.

This report has been reproduced

directly from the best available copy.

Available to DOE and DOE contractors from the

Office of Scientific and Technical Information

P.O. Box 62, Oak Ridge, TN 37831

Prices available from (423) 576-8401

http://apollo.osti.gov/bridge/

Available to the public from the

National Technical Information Service

U.S. Department of Commerce

5285 Port Royal Rd.,

Springfield, VA 22161

http://www.ntis.gov/

OR

Lawrence Livermore National Laboratory

Technical Information Department's Digital Library

http://www.llnl.gov/tid/Library.html 


\title{
Chemical Etch Effects on Laser-Induced Surface Damage Growth in Fused Silica
}

\author{
L. W. Hrubesh, M. A. Norton, W. A. Molander, P. J. Wegner, \\ M. Staggs, S. G. Demos, J. A. Britten, L. J. Summers, \\ E. F. Lindsey and M. R. Kozlowski \\ University of California \\ Lawrence Livermore National Laboratory \\ P. 0. Box 808, L-496 \\ Livermore, CA 94550
}

\begin{abstract}
We investigated chemical etching as a possible means to mitigate the growth of UV laser-induced surface damage on fused silica. The intent of this work is to examine the growth behavior of existing damage sites that have been processed to remove the UV absorbing, thermo-chemically modified material within the affected area.

The study involved chemical etching of laser-induced surface damage sites on fused silica substrates, characterizing the etched sites using scanning electron microscopy (SEM) and laser fluorescence, and testing the growth behavior of the etched sites upon illumination with multiple pulses of $351 \mathrm{~nm}$ laser light. The results show that damage sites that have been etched to depths greater than about $9 \mu \mathrm{m}$ have about a $40 \%$ chance for zero growth with 1000 shots at fluences of 6.8-9.4 $\mathrm{J} / \mathrm{cm}^{2}$. For the etched sites that grow, the growth rates are consistent with those for non-etched sites. There is a weak dependence of the total fluorescence emission with the etch depth of a site, but the total fluorescence intensity from an etched site is not well correlated with the propensity of the site to grow. Deep wet etching shows some promise for mitigating damage growth in fused silica, but fluorescence does not seem to be a good indicator of successful mitigation.
\end{abstract}

Keywords: laser damage, chemical etching, damage growth mitigation, fluorescence diagnostics

\section{INTRODUCTION}

Lawrence Livermore National Laboratory (LLNL) is exploring chemical etching as a possible means to mitigate growth of UV laser-induced surface damage on fused silica. Prior work at this Laboratory studied the effects of chemical etch depth on the damage threshold of fused silica substrates, finding that the treatment improves the damage performance for most cases ${ }^{1,2}$. The study reported here examines the growth behavior of existing damage sites that have been chemically etched to remove the UV absorbing, thermo-chemically modified material within the affected area.

Wet chemical etching of silicate glasses in hydrofluoric acid (HF) based solutions is an age-old process for removing contaminants, shaping optical surfaces, etc., and currently, for patterning integrated circuits. The chemical reactions and the etch rates for removing vitreous silica $\left(\mathrm{SiO}_{2}\right)$ as a function of $\mathrm{HF}$ concentrations and other conditions, are well known from previous studies ${ }^{3}$. Also, the surface morphology which results from the etching process on pre-etch surface features such as scratches, digs and micro-cracks, is well established. Particularly, the dissolution of the silica in the surface feature is isotropic, leading to opening of crack dimensions and, with further etching, to a cusp-like morphology ${ }^{4}$. Laser induced damage craters are similarly affected by HF etching, to the extent that sharp edges are smoothed and cracks are transformed to a smoother, cusp-like surface. This effect is seen in Fig.l which shows a laser produced crater with an internally rough surface, Fig. 1a, and the same crater after HF solution etching removed about 5 micrometers of the surface, Fig. 1b. The chemical etching is thus effective for removing thermo-chemically modified silica material and smoothing any 
cracks within the crater. The elimination of both of these effects from the damage area is believed to be necessary for mitigating growth with subsequent illumination by UV light.

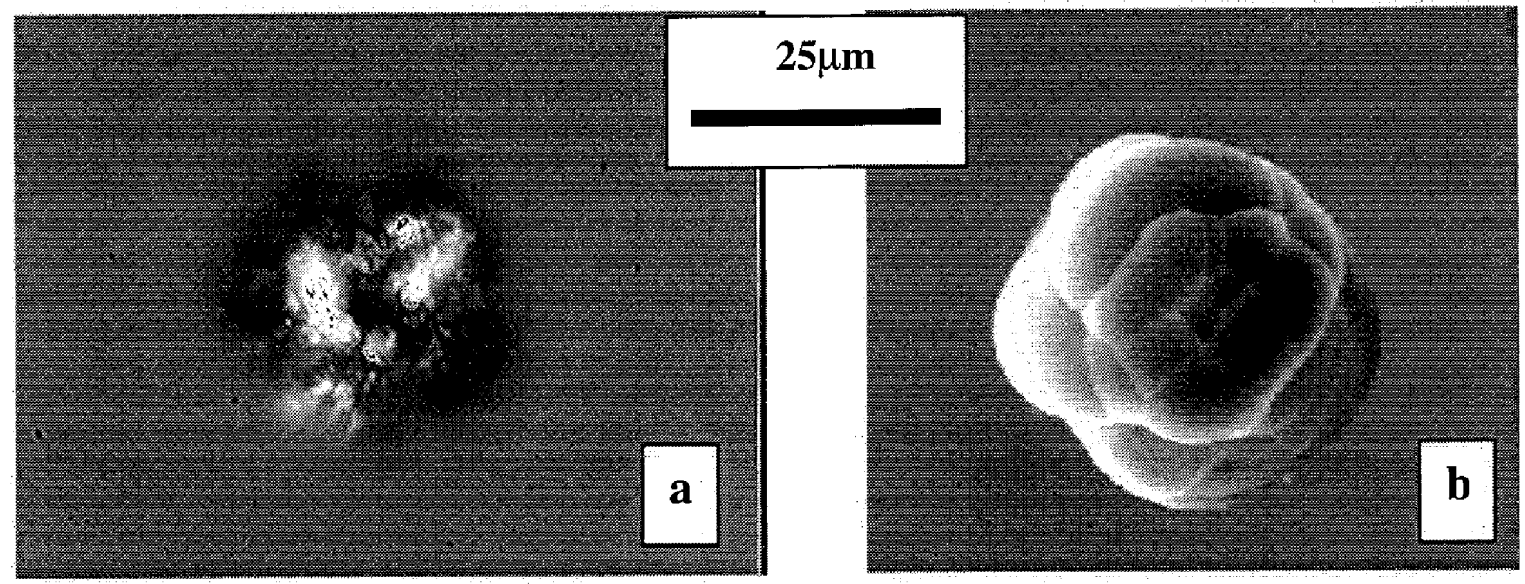

Figure 1. An optical micrograph of a UV laser-induced damage crater in fused silica (a) and an SEM of the same crater (b) after HF solution etching removed $\sim 5 \mu \mathrm{m}$ of silica.

The primary objective of this study is to determine the depth of etching on existing laser-induced damage that is sufficient to eliminate its growth upon repeated illumination of $351 \mathrm{~nm}$ light at a nominal fluence of $8 \mathrm{~J} / \mathrm{cm}^{2}$. A secondary goal is to determine if fluorescence emission from the damage area is correlated with the growth behavior of an etched crater.

\section{EXPERIMENTAL}

In this study, we prepared fused silica substrates with a pattern of laser-induced damage sites. The substrates were etched in a $2 \% \mathrm{HF}$ acid solution for different lengths of time to produce sites with different amounts of removed material. Typical site morphologies were characterized using optical microscopy and SEM. One of the samples was prepared with each damage site etched to a different depth. Fluorescence images were obtained for each site on this sample. Growth tests were performed on the sites by exposing them to pulses from a $351 \mathrm{~nm}$ laser, at a nominal fluence of $8 \mathrm{~J} / \mathrm{cm}^{2}$.

The substrates used for the experiments were Corning 7980 fused silica, with dimensions of $5 \mathrm{~cm}$ diameter by $1 \mathrm{~cm}$ thick. A pattern of nine equally spaced laser induced damage sites were produced on each substrate, using a single $355 \mathrm{~nm}, 7.5 \mathrm{~ns}$ pulse, at a nominal fluence of $45 \mathrm{~J} / \mathrm{cm}^{2}$, for each damage site. Each site consists of a cluster of 10 to $15 \mathrm{small}$ pits. The typical pit size is $20 \mu \mathrm{m}$ diameter by $5 \mu \mathrm{m}$ deep, and the typical cluster diameter is $300 \mu \mathrm{m}$. The sites were etched to different depths, ranging from $0.5 \mu \mathrm{m}$ to $20 \mu \mathrm{m}$, using a buffered $2 \%$ hydrogen fluoride (HF) solution $\left(2 \% \mathrm{HF}, 15 \% \mathrm{NH}_{4} \mathrm{~F}\right.$, $83 \% \mathrm{H}_{2} \mathrm{O}$ ). For some substrates, different etch depths were achieved for selected sites by dipping the part into the etchant for different lengths of time. On another substrate, the etch depth at each site was controlled by using a specially designed micro-fountain to deliver the etchant to a local area of about $50 \mathrm{~mm}^{2}$ surrounding the damage pit. The morphologies of the etched sites were examined using optical microscopy, interferometry and SEM. These analytical methods confirmed the etch depths and the smoothness of the etched sites, relative to the un-etched pits.

Fluorescence images of the etched sites were obtained with the configuration shown in Fig.2. An argon laser is used for excitation at $351 \mathrm{~nm}$. Photoluminescence was detected through a microscope using a cooled CCD detector. Broadband detection revealed primary emission peaks at $470 \mathrm{~nm}$ and $650 \mathrm{~nm}$. The integrated emission intensity from each site was recorded. Sensitive detection at the primary emission wavelengths was accomplished using the appropriate filters and the peak emission intensity was recorded for those wavelengths at each damage site. 


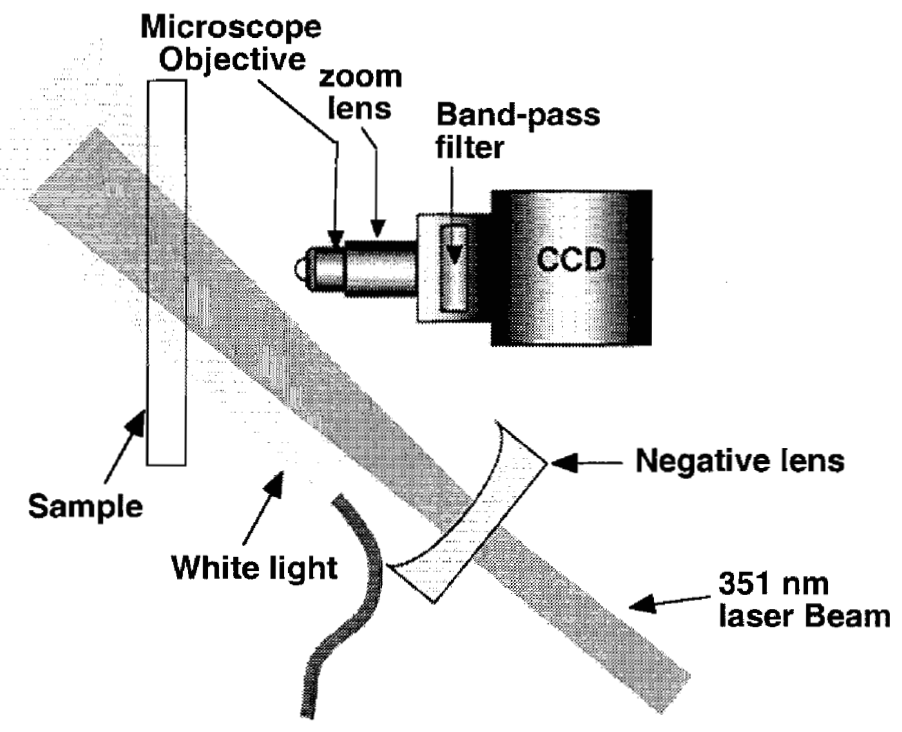

Figure 2. The experimental set-up for exciting and detecting laser-induced fluorescence from damage sites with and without wet chemical etching in HF solution.

through a microscope using a cooled CCD detector. Broadband detection revealed primary emission peaks at $470 \mathrm{~nm}$ and $650 \mathrm{~nm}$. The integrated emission intensity from each site was recorded. Sensitive detection at the primary emission wavelengths was accomplished using the appropriate filters and the peak emission intensity was recorded for those wavelengths at each damage site.

The etched damage sites were tested for growth using a slab Nd:YAG laser at $355 \mathrm{~nm}$ with $\sim 10 \mathrm{~ns}$ laser pulses at 6.8-9.4 $\mathrm{J} / \mathrm{cm}^{2}$. The growth rate is determined by measuring the occluded area as a function of the number of laser shots on the site. Prior work ${ }^{5}$ has determined that after some threshold number of shots, the occluded area, A, grows exponentially with the number of shots, $\mathrm{N}$, at a given fluence, $\mathrm{F}$, ie.,

$$
A=C \cdot \exp (\alpha \cdot N) \text {, for } \alpha=a \cdot F-b \text {. }
$$

The value of $\alpha$ in the exponent is obtained from a fit of the data, and it is used to compare growth rates for chemically etched and un-etched damage sites. Data was accumulated to determine the rate of the growth for sites that grew. The test was terminated after 1000 pulses, if a damage did not grow. An attempt was made to correlate the intensity of fluorescence emission from a given site, with its propensity to grow at all.

\section{RESULTS}

The emission spectrum from a typical un-etched damage crater is shown in Fig.3. Photoemission intensity from a damage site depends on the etch depth and the wavelength suggests the source of luminescence. Three emission peaks are obtained for a $351 \mathrm{~nm}$ excitation wavelength. The peak at $\sim 470 \mathrm{~nm}$ is detected from certain parts of the damage crater and it correlates with the emission from mechanically damaged silica. The peak at $\sim 650 \mathrm{~nm}$ is believed to be due to non-bonding oxygen hole centers (NBOHC). The main peak at $\sim 550 \mathrm{~nm}$ may be due to silicon nano-clusters produced by stripping oxygen from silica. 


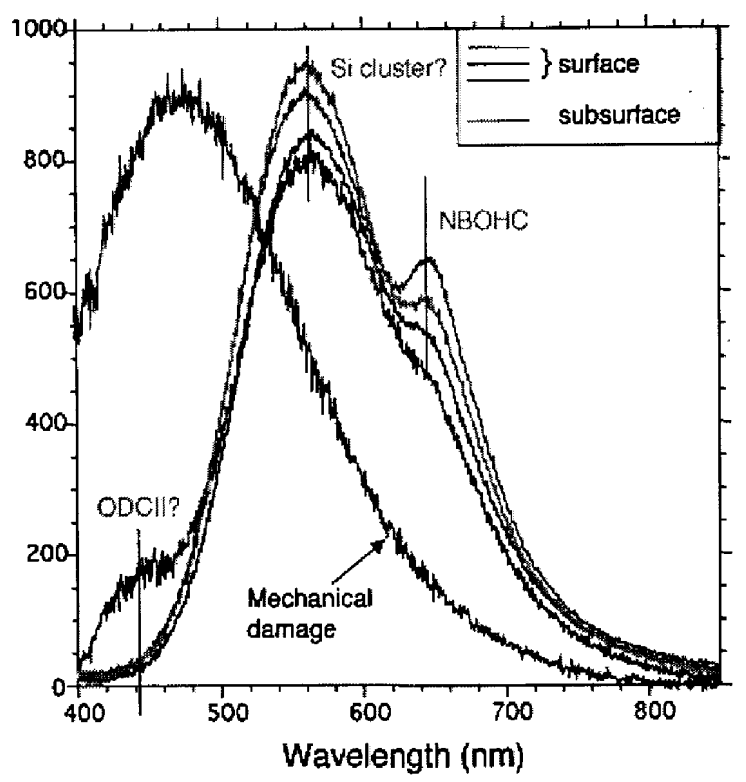

Figure 3. Excitation at $351 \mathrm{~nm}$ yields emission peaks at $\sim 470 \mathrm{~nm}$ (mechanical damage) and $\sim 650 \mathrm{~nm}$ (non-bonding oxygen hole centers). The main peak at $\sim 550 \mathrm{~nm}$ may be due to Si clusters.

One sample with 9 damage sites had 5 sites etched locally using a special technique which delivers the acid solution directly on the site. This method allows damages on the same substrate to be etched to different depths. Figure 4 shows the fluorescence emission at $\sim 470 \mathrm{~nm}$ from sites on the same substrate. The emission intensity is roughly correlated with the depth of etching, as shown in Fig. 5 for the same sample.

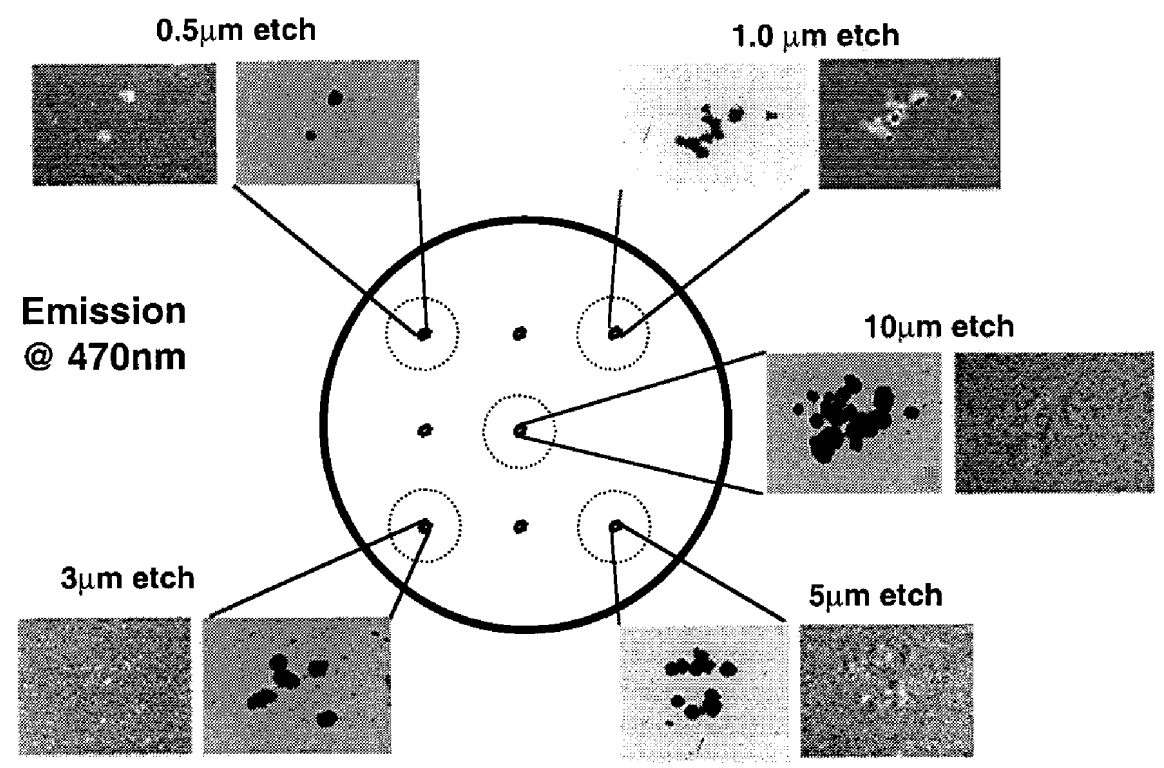

Figure 4. The photoemission at $470 \mathrm{~nm}$ for several damage sites which have been etched to different depths. Photomicrographs of the un-etched sites are shown for comparison. 


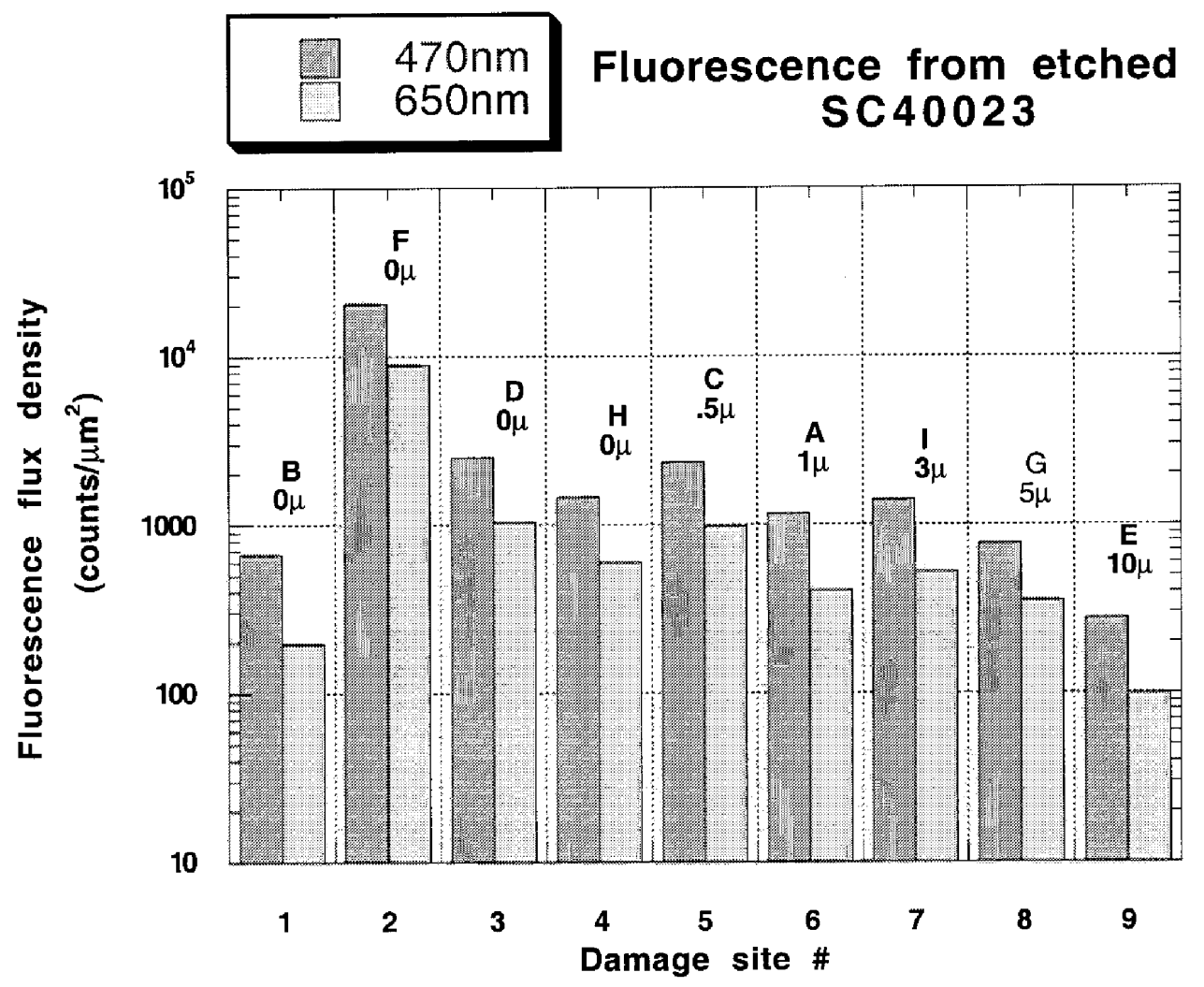

Figure 5. A histogram plot showing the intensity of the fluorescence emission at two wavelengths, from damage sites on a fused silica sample that were chemically etched to different depths using a $2 \%$ HF solution. There appears to be a weak dependence of the fluorescence intensity on the etch depth.

The results of our measurements show that damage sites that have been etched to depths greater than about $9 \mu \mathrm{m}$ have about a $40 \%$ chance for zero growth with 1000 shots at fluences of $6.8-9.4 \mathrm{~J} / \mathrm{cm}^{2}$. For the etched sites that grow at this

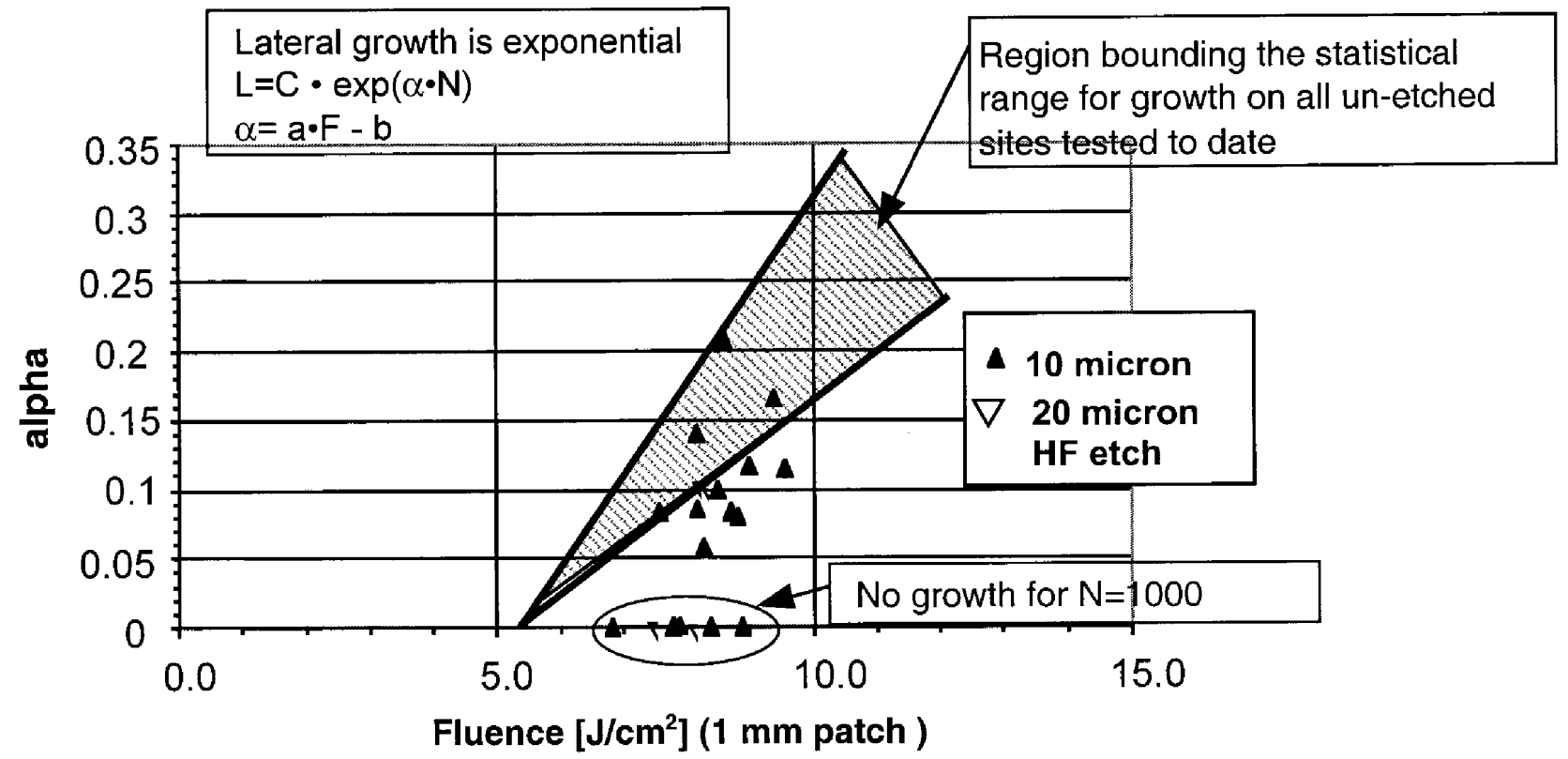

Figure 6. Plot showing results of growth experiments for wet chemical etched damage sites relative to the range of data for un-etched sites. About $40 \%$ of the etched sites did not grow for 1000 shots at the given fluences. 
fluence, the growth rates are consistent with those for non-etched sites. Figure 6 shows the growth data for samples that were etched to depths of $10 \mu \mathrm{m}$ and $20 \mu \mathrm{m}$, as they compare to the statistical range of data for un-etched damage. The data for the growth of wet chemical etched sites is given in table 1 .

Table 1. Tabulated results for growth tests of sites treated with a $2 \%$ HF solution etch.

\begin{tabular}{lcccc}
\hline Sample & Site & Etch depth $(\mu \mathrm{m})$ & Test fluence $\left(\mathrm{J} / \mathrm{cm}^{2}\right)$ & Shots to growth \\
\hline \multirow{2}{*}{ SC40021 } & G & 10 & 7.8 & $1000+$ \\
& D & 10 & 6.8 & $1000+$ \\
& I & 10 & 8.9 & $1000+$ \\
& F & 10 & 9.4 & 40 \\
& H & 10 & 8.4 & $1000+$ \\
SC40023 & E & 10 & 8.4 & $1000+$ \\
& C & 0.5 & 7.8 & 3 \\
& A & 1 & 7.5 & 1 \\
& I & 3 & 8.4 & 3 \\
& G & 5 & 8.1 & 1 \\
SC40026 & E & 10 & 8.1 & 24 \\
& A & 10 & 8.2 & 17 \\
& B & 10 & 8.1 & $1000+$ \\
& C & 10 & 8.1 & 19 \\
& D & 10 & 7.8 & 23 \\
& E & 10 & 8.5 & 10 \\
SC40027 & F & 10 & 8.4 & $1000+$ \\
& F & 20 & 8.4 & 3 \\
& E & 20 & 8.2 & $1000+$ \\
& H & 20 & 8.5 & \\
& G & 20 & 7.4 & \\
\hline
\end{tabular}

\section{CONCLUSIONS}

Chemical etching of heavily laser damaged sites has been shown to raise the growth threshold for some etched sites. Measurable fluorescence emission at $470 \mathrm{~nm}$ and $650 \mathrm{~nm}$ is common or all sites, un-etched or etched. The intensity of fluorescence reduces with deeper etching (material removal) of the site.

Deeply etched sites show reduced, but non-zero, fluorescence emission.

Deep chemical etching with $2 \% \mathrm{HF}$ solution stops growth for about $40 \%$ of damage sites on silica and it slows the growth rate for the sites that grow. There is a weak dependence of the total fluorescence emission with the etch depth of a site. However, the total fluorescence intensity from an etched site is not well correlated with the propensity of the site to grow.

We conclude that deep chemical etching shows some promise for mitigating damage growth in fused silica, but fluorescence does not seem to be a good indicator of successful mitigation. 


\section{ACKNOWLEDGEMENTS}

This work was performed under the auspices of the U.S. Department of Energy by University of California Lawrence Livermore National Laboratory under contract No. W-7405-Eng-48.

\section{REFERENCES}

1. J.M. Yoshiyama, F.Y. Genin, A. Salleo, I.M. Thomas, M.R. Kozlowski, L.M. Sheehan, I.D. Hutcheson, D.W. Camp, "Effects of polishing, etching, cleaving, and water leaching on UV laser damage of fused silica," Laser-Induced Damage In Optical Materials-1997, SPIE Vol. 3244, pp.331-340, October 1997.

2. C.L. Battersby, L.M. Sheehan and M.R. Kozlowski, "Effects of Wet Etch Processing on Laser-Induced Damage of Fused Silica Surfaces," Laser Induced Damage in Optical Materials - 1998, SPIE Vol. 3578, pp. 392-400, Oct. 1998.

3. G.A.C.M. Spierings, "Wet chemical etching of silicate glasses in hydrofluoric acid based solutions," J. Mater. Science 28, pp. 6261-6273, 1993.

4. G.A.C.M. Spierings, "Surface roughness of silicate glasses etched in hydrofluoric acid solutions," J. Mater. Science 26, pp. 3329-3332, 1991.

5. M.A. Norton, Z. Wu, L.W. Hrubesh, A. M. Rubenchik, M.D. Feit, D. Milam, W.A. Molander, P. Wegner, M.R. Koslowski, "Growth of Laser Initiated Damage in Fused Silica at 351nm," These Proceedings, October 2000. 